0 mundo dos antepassados e o mundo dos vivos ritual de ukanyi na mediação: um ensaio sobre ancestralidade no Sul de Moçambique ${ }^{1}$

\section{The world of the} ancestors and the world of the living ukanyi ritual in mediation: an essay on ancestry in south of Mozambique

\section{Dulcídio Manuel Albuquerque Cossa} Universidade do Estado do Rio de Janeiro (UERJ) dmacossa@gmail.com

DOI: https://doi.org/10.22481/odeere.v4i7.5370

\footnotetext{
${ }^{1}$ O presente trabalho foi realizado com apoio do CNPq - Brasil, no âmbito da pesquisa de doutorado e mestrado sob orientação da Prof. Dra. Marcia Contins, no Programa de Pós-
}

RESUMO: O objetivo deste artigo é pensar como a relação entre o mundo dos antepassados e o mundo dos vivos se estabelece e se estrutura por intermédio do ritual de ukanyi (um ritual realizado para o consumo da bebida-ancestral-sagrada ukanyi). Proposta esta que remete ao estudo e compreensão da religiosidade tradicional africana, na qual se assenta a cosmovisão dos africanos perpassada por um sistema de valores, crenças e práticas bantu. Assim, o método etnográfico e a análise situacional aparecem como alicerces para compreender o fenômeno em causa. Considero o pressuposto de que o ritual de ukanyi é uma cerimônia que permite a exaltação dos antepassados, ativa e reativa valores, crenças e práticas que fortalecem e revigoram a religiosidade tradicional africana. Dessa forma, o mesmo nos possibilita vivenciar e experimentar dois mundos diferentes, dos vivos e dos mortos (antepassados). Entendo que compreender a relação entre o mundo dos vivos e dos antepassados é adentrar na forma como se constituem as afrofilosofias que permitem tangenciar o universo africano.

Palavras-chave: Ritual de ukanyi. Mundo dos vivos. Mundo dos mortos. Antepassados.

ABSTRACT: The objective of this article is to think how the relation between the world of the ancestors and the world of the living ones is established and is structured by means of the ukanyi ritual (a ritual realized for the consumption of the drink-ancestral-sacred ukanyi). This proposal refers to the study and understanding of traditional african religiosity, which is based on the world view of africans permeated by a system of bantu values, beliefs and practices. Thus, the ethnographic method and the extended case method appear as foundations to understand the phenomenon in question. I consider the assumption that the ukanyi ritual is a ceremony that allows the exaltation of the ancestors, active and reactive values, beliefs and practices that strengthen and reinvigorate traditional african religiosity. In this way, it enables us to living and experience two different worlds, the living and the dead (ancestors). I understand that understanding the relationship between the world of the living and the ancestors is to penetrate the way in which the afro-philosophies are constituted that allow us to touch the african universe.

Keywords: Ukanyi Ritual. World of the living. World of the dead. Ancestors.

Graduação em Ciências Sociais (PPCIS). Instituto de Ciências Sociais (ICS). Departamento de Antropologia Universidade do Estado do Rio de Janeiro (UERJ). 


\section{Introdução}

Primeiramente, importa referir que este trabalho é resultado de uma pesquisa de doutorado não acabada, mas em andamento. Uma pesquisa na qual, eu enquanto pesquisador negro, africano, moçambicano sou atravessado pelo contexto pesquisado, o qual faço parte. $E$, portanto, o ritual em causa (ritual de ukanyi/mhamba ya ukanyi) me é familiar desde a infância, o que pressupõe implicações tanto acadêmicas como pessoais. Contudo, as mesmas não são o foco da minha análise no presente artigo.

Entre os meses de janeiro e março, algumas comunidades das províncias de Maputo, Gaza e Inhambane, na região Sul de Moçambique², celebram a época de ukanyi. Época tradicionalmente tida como Nguva ya ukanyi ${ }^{3}$, é o período em que se realiza uma série de rituais afins a ukanyi, momento de efervescência coletiva, caracterizado por uma forte movimentação de pessoas motivadas por esta série de cerimônias. Justamente é a ocasião em que a abundância de ukanyi (bebida) e makanyi (frutos) se faz presente no cotidiano dos indivíduos. Assim, a época de ukanyi vai desde a frutificação de makanyi, a coleta destes frutos, a produção da bebida ukanyi até a realização dos rituais comuns à bebida e para a época.

Ukanyi ${ }^{4}$ é uma bebida tradicional-sagrada-ancestral produzida a partir dos frutos de uma árvore (Marula), em Moçambique localmente conhecida como nkanyi, também denominada canhueiro, e cientificamente conhecida como Sclerocarya birrea. É uma árvore fruteira que ocorre em alguns países do continente africano tais como Moçambique, África do Sul, Namíbia, Suazilândia, Zimbábue, Botsuana, na África Equatorial (entre a Etiópia e o Sudão, a Norte), entre outros.

Na África do Sul, os frutos do nkanyi são usados para produzir uma bebida de nome Amarula. Na região Sul de Moçambique, sobretudo nas províncias de Maputo e Gaza (meus campos de pesquisa), os frutos do nkanyi são conhecidos como makanyi (plural) ou kanyi (singular) e usados, sobretudo, para a produção da bebida-ancestral-sagrada de nome ukanyi.

Ukanyi é uma bebida de pouco teor alcoólico e não é alucinógena. Pode ser consumido/a por qualquer indivíduo de sexo masculino e/ou feminino sem discriminação de idade. Contudo, às

\footnotetext{
2 Moçambique, oficialmente designado República de Moçambique, com a sua capital Maputo (que foi chamada Lourenço Marques durante a dominação portuguesa), localiza-se na costa oriental da África Austral, limitado a norte pela Tanzânia, a noroeste pelo Malaui e Zâmbia, a oeste pelo Zimbábue, a leste pelo Canal de Moçambique e Oceano Índico, e a sul e sudoeste pela África do Sul e Suazilândia. Tem uma área de $801.590 \mathrm{~km}^{2}$ e uma população estimada em 20.069.738 habitantes (dados de 2007). Obteve a sua independência a 25 de Junho de 1975, após quase cinco séculos de dominação colonial estrangeira imposta por Portugal. Faz parte da Comunidade dos Países de Língua Portuguesa. Disponível em: < http://www.portaldogoverno.gov.mz/por/Mocambique>. Acesso em: 07 dez. de 2016.

${ }^{3}$ Nome em xichangana, língua local, que significa época da bebida de canhú.

${ }^{4}$ Nome em língua local (xichangana).
} 
crianças só se recomenda o suco de ukanyi ainda doce, que não tenha fermentado, ou seja, que não tenha teor alcoólico.

As sementes de makanyi (concretamente as amêndoas) são chamadas de timongo em xichangana e xirhong $a^{5}$ e servem para usos diversos, como aproveitar o seu caroço, que é conotado como tendo poder de fortalecer a virilidade masculina. Timongo também servem para produzir óleo alimentar. Assim, timongo (amêndoas) e makanyi (frutos) detêm de um valor nutritivo.

Importa ressaltar que a difusão da árvore (nkanyi) no continente africano deu-se por intermédio do povo bantu. Por ser um importante produto alimentar na dieta do povo bantu desde os primórdios, eles levaram consigo as sementes em todas as suas peregrinações, que eram utilizadas, entre outras coisas, para a prática dos jogos de covas. Além disso, o fruto constitui uma boa fonte de alimentação, pois é rico em gorduras e proteínas. Nos dias atuais, a polpa ainda pode ser usada para a fabricação de etanol. O chá das flores também auxilia no tratamento da indigestão alimentar. O caroço é utilizado na África do Sul para se fazer um óleo que serve como protetor da pele. Em Moçambique, o caroço também é utilizado para se praticar os jogos de covas. Na medicina tradicional dos antepassados moçambicanos, a casca interna do nkanyi (canhoeiro) era usada para tratamento da malária, tosse, aftas, hemorróidas e no alívio às picadas de escorpiões e cobras. A raiz é usada para o tratamento de diarréias. O chá produzido pelas folhas é usado para o tratamento de indigestão e dores de ouvido ${ }^{6}$.

Esta bebida (ukanyi) é geralmente produzida por mulheres, tanto no contexto rural (como Macuane) bem como no contexto tendencialmente urbano (como Marracuene), ambos os espaços que são meus campos de pesquisa. O envolvimento dos homens no processo de produção não é comum, visto que, durante a época de ukanyi, os homens envolvem-se em outras atividades relativas ao ritual de ukanyi. Assim, no processo do ritual de ukanyi, as atividades são divididas de acordo com o gênero.

A produção da bebida ancestral-sagrada ukanyi é um processo que leva alguns dias até que esta fique pronta. Deste modo, quando chega a época de ukanyi e se aproxima uma cerimônia de consumo de ukanyi, as mulheres reúnem-se em grupos para começar a apanha/recolha de makanyi (frutos de nkanyi - canhueiro) para a produção da bebida sagrada. Recolhidos os frutos do conhueiro, são juntados num único lugar e daí as mulheres decidem em consenso um dia para elas

\footnotetext{
${ }^{5}$ Ambas línguas do Sul de Moçambique.

${ }^{6}$ PEREIRA, Rinaldo. Pontencialidades do jogo africano Mancala IV para o campo da educação matemática, história e cultura africana. 2016. 337f. Tese (Doutorado em Educação) - Faculdade de Educação, Universidade Federal do Ceará, Fortaleza, 2016.
} 
em conjunto prepararem a bebida.

Chegado o dia da produção da bebida, as mulheres furam makanyi com ajuda de objetos pontiagudos, tais como facas e garfos e juntam-nos num recipiente maior, tradicionalmente 0 recipiente usado para tal é chamado de khuwane ${ }^{7}$ e na falta deste, sobretudo nos dias de hoje, usase também o tambor, geralmente plástico. No khuwane, junto à makanyi, vai um pouco de água e faz-se a mistura.

Feito isso, espreme-se makanyi, deixando ficar apenas o seu suco no pote (khuwane) por um dia para que fermente, isto no primeiro dia. Já no segundo dia, quando ukanyi está fermentado, espreme-se mais makanyi para que ukanyi fermentado se junte ao suco doce de makanyi recémespremido e deixa-se ficar mais um dia. E só no terceiro dia, ukanyi é considerado pronto para ser bebido e para se fazer a festa ritual. Porém, antes da fermentação, o suco doce de ukanyi é reservado para as crianças e outras pessoas que não consumam bebidas alcoólicas.

É também tarefa das mulheres confeccionar os alimentos a serem consumidos na cerimônia, e como geralmente a época de ukanyi coincide com a época de colheita, são comuns os pratos tradicionais com sacrifícios de animais. Neste caso, por outro lado, os homens se responsabilizam por sacrificar tais animais.

A etapa da preparação do ritual de ukanyi é, no entanto, um dos momentos em que homens e mulheres por meio das conversas compartilham seus conhecimentos, suas vivências e as experiências do seu cotidiano, e mais ainda, é um período no qual estes encontram-se mais próximos uns dos outros, unidos pela mesma causa - a celebração da festa ritualística.

Desde o início ou desde a etapa da preparação do ritual de ukanyi, tanto as mulheres quanto os homens vão criando e estabelecendo uma rede de relações presentes nas interações sociais que Ihes são sujeitos pela divisão social do trabalho, como diria Durkheim ${ }^{8}$. É interagindo uns com os outros originando um entrelaçamento forte de relações sociais que se garante o sucesso do ritual de $u$ kanyi bem como da época em geral. E ao fazer isso, parafraseando Garfinkel ${ }^{9}$, vão criando uma ordem negociada, temporária, frágil que deve ser permanentemente reconstruída. Portanto, essa etapa permite que haja uma interação por via de canções e de conversas que vão sendo tecidas em torno do cotidiano fazendo com que seja um momento de manutenção das relações sociais por

\footnotetext{
${ }^{7}$ Khuwane é o nome atribuído ao pote de barro usado para conservar ukanyi. Não é de uso exclusivo para a conservação de ukanyi, pois pode ser usado também para conservar água.

${ }^{8}$ DURKHEIM, Émile. A divisão social do trabalho. Rio de Janeiro: Martins Fontes, 2000.

${ }^{9}$ GARFINKEL, Harold. Estudos da etnometodologia. Cambridge: Polity presse, 1967.
} 
excelência ${ }^{10}$.

No local do ritual, homens sentam-se de um lado e as mulheres de outro. Ukanyi é colocado em potes de barro denominados khuwane e ao lado dos potes vão os alguidares de barro chamados lihisu $^{11}$, onde são conservadas as cabaças ndzheko ${ }^{12}$ usadas para servir e beber ukanyi. No final do ritual os alguidares são usados para conservar o hongwe ${ }^{13}$, o qual constitui a bebida que fica no fundo do pote. Acredita-se que o alto teor afrodisíaco de ukanyi está mais concentrado no hongwe, já que tem o poder de fortalecer a potência sexual, daí que, reza a tradição que o hongwe só deve ser consumido por indivíduos que tenham parceiros, sobretudo homens, na tentativa de evitar situações de adultério ou traição. Segundo as crenças locais, ukanyi é uma bebida que detém de um poder afrodisíaco, poder esse que é ancestral.

Para manter o ritual de ukanyi mais animado, o mesmo é sistematicamente acompanhado de canções folclóricas, embaladas ao ritmo de palmas, que retratam o cotidiano dos indivíduos. Os cânticos são simultaneamente acompanhados de danças tradicionais, entretanto, tanto estas (danças) como aqueles (cânticos), mais do que animar, são mecanismos legitimadores das interações sociais estabelecidas, uma vez que pressupõem uma relação entre quem as canta e dança e quem as acompanha. E mais ainda, parte das canções e danças do ritual faz referência aos antepassados.

Este artigo é decorrente de constatações feitas durante o meu trabalho de campo a quando da minha formação de mestrado, entre o ano de 2015 e 2017. Campo esse que continuo explorando atualmente no doutorado. É uma tentativa de refletir o campo da religiosidade africana por meio de sua dimensão sensível e por isso, se calhar mais complexa, que é a relação entre os vivos e os mortos. Portanto, me proponho a pensar em como a relação entre o mundo dos vivos e o mundo dos mortos se estabelece e se estrutura através do ritual de ukanyi. Assim, o método etnográfico e a análise situacional aparecem como alicerces para compreender o fenômeno em causa, entrelaçando-o a perspectivas de alguns teóricos.

O ritual de ukanyi seria, então, uma cerimônia festiva que se organiza no Sul de Moçambique, com mais incidência para as províncias de Maputo e Gaza, com o intuito de consumir esta bebida tradicional-sagrada-ancestral ukanyi que marca a época de colheita e que revigora o

\footnotetext{
${ }^{10}$ COSSA, Dulcídio. Mhamba ya ukanyi (O ritual de ukanyi): uma tradição na modernidade - entrelaçamentos do rural e urbano. 2017. 196 f. Dissertação (Mestrado em Ciências Sociais) - Instituto de Ciências Sociais, Universidade do Estado do Rio de Janeiro, Rio de Janeiro, 2017.

${ }^{11}$ Nome em língua local (xichangana) atribuído ao alguidar que conserva ndzheko e hongwe.

${ }^{12}$ Nome em língua local (xichangana) atribuído as cabaças usadas para beber ukanyi.

${ }^{13}$ Nome em língua local (xichangana) atribuído à parte mais densa de ukanyi onde existe a maior concentração do teor afrodisíaco desta bebida tradicional.
} 
convívio com os antepassados.

Este ritual se constitui em três etapas: kuhawula mindzheko (ritual de abertura), xikuwha (auge/ápice do ritual) e kuhayeka mindzheko (ritual de encerramento). Portanto, cumprir com estas três etapas implica passar pelos momentos que Van Gennep ${ }^{14}$ e Turner $^{15}$ denominaram de separação (kuhawula mindzheko), liminaridade (xikuwha) e de reagregação (kuhayeka mindzheko), completando assim o ciclo do ritual de ukanyi.

O ritual de ukanyi começa por uma etapa, um ritual denominado kuhawula mindzheko ${ }^{16}$, onde se realiza um outro rito denominado kuphahla (rito de invocação dos antepassados), que segundo os meus interlocutores é o momento em que se anuncia a abertura oficial da época de ukanyi e a partir deste ato fica liberado o seu consumo, o que significa ser expressamente proibido a sua ingestão antes de realizado o ritual sob o risco de ser penalizada a pessoa que eventualmente transgredir esta regra.

Kuhawula mindzheko é o período em que se anuncia aos antepassados a chegada da época de ukanyi e que se roga aos mesmos para o sucesso desta. Não se pode beber ukanyi sem antes comunicá-los ${ }^{17}$, sob risco de profanar, não só a bebida, mas também os antepassados. Estas proibições levam a pensar num conjunto de normas que condicionam a realização do ritual e orientam a conduta dos indivíduos e consequentemente nos remetem a questões jurídicas, ou seja, ao que chamaríamos de direito intercultural, aqui relacionado ao conjunto de normas tradicionalmente instituídas ou institucionalizadas que regem um grupo ou grupos de indivíduos.

Cumprido o kuhawula mindzheko e posteriormente liberado o consumo de ukanyi vem a outra etapa: a grande festa ou o auge do ritual de ukanyi, denominado xikuwha. Este é o momento mais alto da festa tradicional popular de ukanyi, o qual simboliza o encontro entre os membros de uma comunidade ou de várias comunidades. Portanto, é a celebração em que os sujeitos confraternizam, convivem e interagem uns com os outros celebrando a época de $u$ kanyi ${ }^{18}$.

Entretanto, não é simplesmente uma reunião entre os indivíduos, mas um encontro destes com os antepassados por via de alguns atos rituais, como o kuphahla ${ }^{19}$, tido com uma prática presente em todos os rituais de ukanyi e em todas as etapas do ciclo da época de ukanyi. Mais do

\footnotetext{
${ }^{14}$ VAN GENNEP, Arnold. Os ritos de passagem. Petrópolis: Editora Vozes, 2011.

15 TURNER, Victor. O Processo Ritual: Estrutura e Anti-Estrutura. Petrópolis: Editora Vozes, 2013.

${ }^{16}$ Nome atribuído a este ritual em língua local (xichangana).

${ }^{17}$ COSSA, Dulcídio. Mhamba ya ukanyi (O ritual de ukanyi): uma tradição na modernidade - entrelaçamentos do rural e urbano. 2017. 196 f. Dissertação (Mestrado em Ciências Sociais) - Instituto de Ciências Sociais, Universidade do Estado do Rio de Janeiro, Rio de Janeiro, 2017.

18 Ibidem.

${ }^{19}$ Nome em língua local (xi changana) atribuído ao ritual de invocação dos ancestrais.
} 
que para invocar os antepassados existe também a crença comum de que kuphahla é o meio através do qual estes bebem e desfrutam do ukanyi e mantêm-se presentes no ritual.

Portanto, estas crenças são comportamentos de senso comum que segundo Garfinkel ${ }^{20}$ são os constituintes necessários de todo o comportamento socialmente organizado. E, é assim que os sujeitos vêem, descrevem e propõem em conjunto uma definição da situação social do ritual ${ }^{21}$.

Após o xikuwha, realiza-se um último ato ritual: kuhayeka mindzheko ${ }^{22}$, esta é a etapa na qual se anuncia aos antepassados o fim da época de ukanyi e em que se presta agradecimento aos ancestrais pelo sucesso da época ou faz-se a exposição dos dissabores ocorridos, pedindo para que não se repitam em situações vindouras.

Deste modo, quando chega a época de ukanyi, o Sul de Moçambique literalmente pára, a fim de vivenciar e testemunhar esse momento, reverenciando assim os antepassados. Ressaltar que todo o processo ritual de ukanyi dura cerca de três a quatro meses, de dezembro/janeiro a março, que geralmente constitui o período de abundância de ukanyi.

Importa também afirmar que o ritual de ukanyi é geralmente dirigido pelo líder local que é o superior hierárquico e representante da comunidade, conhecido tradicionalmente como mukhulu ou hosi (chefe), sendo este o primeiro a beber ukanyi e intermedia a comunicação com os antepassados através dos rituais de invocação.

A cerimônia é dirigida em língua local xichangana para o caso de Macuane e xirhonga em Marracuene, por sinal estas são as línguas mais fluentes durante o ritual, uma vez que constituem os idiomas nativos destes contextos sociais. Na etnometodologia de Garfinkel ${ }^{23}$ esses idiomas equivaleriam à indicialidade, segundo a qual, a vida social se constitui através da linguagem da vida de todos os dias, tendo em vista que as expressões indiciais, neste caso de xichangana e xirhonga, tiram o seu sentido do próprio contexto social. Ademais, falar xichangana e/ou xirhonga implica domínio da linguagem institucional comum, que é um elemento fundamental para que os indivíduos se sintam ou sejam considerados membros da comunidade, pois a noção de membro não se refere a pertença social, mas ao domínio da linguagem natural, atendendo e considerando o contexto social ${ }^{24}$. Destarte, o ritual de ukanyi é também um momento de valorização, revitalização e

\footnotetext{
${ }^{20}$ GARFINKEL, Harold. Estudos da etnometodologia. Cambridge: Polity presse, 1967.

${ }^{21}$ COSSA, Dulcídio. Mhamba ya ukanyi (O ritual de ukanyi): uma tradição na modernidade - entrelaçamentos do rural e urbano. 2017. 196 f. Dissertação (Mestrado em Ciências Sociais) - Instituto de Ciências Sociais, Universidade do Estado do Rio de Janeiro, Rio de Janeiro, 2017.

${ }^{22}$ Nome atribuído a este ritual em língua local (xichangana).

${ }^{23}$ GARFINKEL, Harold. Estudos da etnometodologia. Cambridge: Polity presse, 1967.

${ }^{24}$ COSSA, Dulcídio. Mhamba ya ukanyi (O ritual de ukanyi): uma tradição na modernidade - entrelaçamentos do rural e urbano. 2017. 196 f. Dissertação (Mestrado em Ciências Sociais) - Instituto de Ciências Sociais, Universidade do Estado do Rio de Janeiro, Rio de Janeiro, 2017.
} 
afirmação da língua tradicional ou local, ao mesmo tempo que vai sendo intercalada com o português.

As situações sociais aqui narradas decorreram em Moçambique, na província de Gaza, distrito de Bilene, concretamente em Macuane, interior do distrito - região Sul do país. E em Marracuene, distrito também situado no Sul do país, na província de Maputo. Macuane é um posto administrativo que integra as localidades de Chichango, Macuane e Tuane Oriental ${ }^{25}$ e faz parte dos seis postos administrativos que compõem o distrito de Bilene, de entre os quais: Chissano, Macia, Mazivila, Messano e Praia do Bilene. Enquanto que Marracuene, a sua sede é a Vila de Marracuene e está dividido em dois postos administrativos: Machubo e Marracuene.

A escolha dos campos de pesquisa deveu-se a necessidade de permitir uma análise que relacionasse a manifestação deste mesmo ritual (de princípio de origem rural) em dois contextos diferentes, o que ampliaria mais a visão sobre a compreensão do objeto. Sendo Macuane um espaço rural e Marracuene, urbano.

Assim, procurarei primeiro, por via de algumas situações sociais ${ }^{26}$ vividas durante o meu trabalho de campo, debruçar-me sobre certos elementos que nos sugerem ao tema aqui proposto, para de seguida articulá-los com algumas abordagens teóricas de autores que se dedicaram ao estudo da relação entre o mundo visível e o mundo invisível.

Diante a suma importância que os mortos revelam ter para os vivos em Macuane e Marracuene e das lacunas que os autores não deram conta nos estudos sobre a relação entre o mundo visível e o mundo invisível, proponho-me a empreender uma análise que permita a partir do ritual de ukanyi (mhamba ya ukanyi) aprofundar a compreensão da relação entre estes mundos tão "distantes" quanto "próximos".

\section{Ritual de ukanyi mediando entre o mundo dos antepassados e o mundo dos vivos}

Pelo que se pôde notar do trabalho de campo feito e da discussão que tenho sugerido, o ritual de ukanyi estabelece uma série de mediações socioculturais decorrentes de inúmeras oposições. Assim, dentre elas, urge a necessidade de aprofundar e compreender a mediação entre o mundo dos vivos e o mundo dos mortos, que decorre de oposições que se manifestam nas práticas

\footnotetext{
${ }^{25}$ Disponível em “http://pt.wikipedia.org/w/index.php?title=Bilene_Macia_(distrito)\&oldid=27509127" Acessado em: 2 Abr. 2012.

${ }^{26}$ GLUCKMAN, Max. Custom and Conflit in Africa. Oxford: Blackwell, 1995. Uso a categoria "situações sociais" como referência a Gluckman em seu "método de análise situacional" usado, sobretudo, em seu ensaio Análise de uma situação social na Zululândia moderna.
} 
do cotidiano dos indivíduos de Macuane e Marracuene. Estas práticas envolvem formas de agir, pensar e sentir dos indivíduos, que visivelmente emergem no ritual de ukanyi (mhamba ya ukanyi), ou na época do ritual (nguva ya ukanyi). E estas práticas perfazem o sistema de religiosidade tradicional africana, particularmente de Macuane e Marracuene. Portanto, esta oposição está praticamente patente em todo o ciclo ritual da festa de ukanyi.

Deste modo, é imprescindível tecer algumas considerações sobre como é que o ritual de ukanyi estabelece a mediação entre o mundo dos vivos e o mundo dos mortos. Para isso, remeto a análise a uma situação específica do meu trabalho de campo.

A quando da minha ida a Macuane, onde ia presenciar o ritual kuhayeka mindzheko, que seria a festa de encerramento do ciclo da época de ukanyi e que, por sinal, decorreria na casa da família real ${ }^{27}$ Cossa/Khosa, vivenciei uma situação que me despertou bastante atenção. 0 fato é que, chegado ao local, reinava um ambiente muito calmo naquele espaço, todos conversavam em voz baixa, ou quase não conversavam; os anciãos concentrados com o mukhulu/hosi (chefe) falavam bem baixinho. Era um ambiente melancólico e atípico, se comparado aos que tínhamos vivido em outras sessões de ukanyi.

Eis que um ancião toma a palavra e anuncia a morte de um membro da comunidade, por sinal, vizinha da família real, o que justificava a ausência de um dos mestres de cerimônias que habitualmente se fazia presente nas sessões de ukanyi, pois era parente da malograda. Tratava-se de uma anciã que teria sucumbido de uma doença. A comunidade de Macuane estava de luto.

Desse modo, acordou-se em consenso que a cerimônia não decorreria de acordo com o protocolo tradicional habitual. Ou seja, não havia condições de realizar o ritual kuhayeka mindzheko naquele dia, pois este é um ritual festivo, porque marca o fim de uma época que deve ser celebrada e aclamada. Entretanto, o ambiente instalado na comunidade era de luto e não de festa. Consequentemente, o ritual kuhayeka mindzheko foi remarcado para outro dia adequado. Não obstante, como a bebida sagrada já tinha sido preparada e não podia ser deixada para outro dia, sob risco de se estragar, e os participantes estavam presentes em massa, o hosi/mukhulu (chefe) Cossa decidiu anunciar que se devia beber ukanyi até que acabasse, mas num ambiente tranquilo, de calma, sem canções nem dança, sem palmas nem gritos, absoluto silêncio como forma de honrar a memória da malograda/finada. E a partir daí os participantes do ritual começaram a se mobilizar no sentido de tomar conta do sucedido.

\footnotetext{
${ }^{27}$ A família real, no caso de Moçambique, seria aquela dos líderes locais conhecidos no Sul do país, e particularmente em Macuane e Marracuene como mukhulu ou hosi, que representam a autoridade tradicional. Líderes que a partir do período colonial foram denominados "régulos". A sucessão de liderança é passada de geração para geração por herança no seio da família real.
} 
Aquele ambiente de luto, de melancolia, todo aquele conjunto de fatos era o campo tentando me revelar algo sobre a estrutura social de Macuane, ou seja, aquela situação desvendava a forma como a rede de solidariedade funciona na comunidade de Macuane, pois, com aquela morte na comunidade, acionara-se o espírito de comunalismo ${ }^{28}$ e de respeito ao próximo, neste caso à família enlutada. E mais, a coincidência da morte da anciã justamente no dia da realização do ritual ancestral era entendida também como uma benção para a malograda, pois decorrida num dia de exaltação dos antepassados.

Ora, este respeito ao próximo revela-nos não só o respeito que se tem com os vivos, mas, sobretudo, a relação que se tem com os mortos, neste caso concreto a malograda anciã que do mundo dos vivos partiu para o dos mortos, passando a pertencer ao mundo dos antepassados de Macuane pela sua importância na comunidade como detentora da sabedoria popular, pois reina naquele contexto uma crença segundo a qual os anciãos são bibliotecas vivas, estes portam o conhecimento sobre os valores da comunidade e do mundo. De salientar que, acredita-se que os antepassados se mantêm presentes no cotidiano dos indivíduos na comunidade.

Por conseguinte, isto implica que na comunidade de Macuane existe uma estrita ligação entre o mundo dos vivos e o mundo dos mortos (antepassados), ligação essa que remete a uma relação, na qual ambos os mundos interagem continuamente, razão pela qual quando se bebe ukanyi deita-se parte da bebida para o chão como forma de dar de beber aos antepassados. E quando se faz a abertura da época de ukanyi realiza-se um ritual denominado Kuphahla, no qual os antepassados são invocados para abençoar a época e liberar o consumo de ukanyi. E, no final da época, realiza-se de novo o ritual em que os antepassados são novamente invocados para dá-los o relatório da época de ukanyi e agradecê-los pela mesma, sinal de que os antepassados se fazem presentes no ritual de ukanyi e no cotidiano dos macuaneses assim como dos marracueneses, visto que em Marracuene também se realiza.

Kuphahla é o marco da fase inicial de todo o processo e o momento principal para dar partida à época de $u k a n y i$, tradicionalmente denominada nguva ya $u k a n y i^{29}$, pois é neste ritual em que o líder tradicional hosi/mukhulu (patriarca) anuncia aos antepassados que a época de ukanyi está a começar. E assim, com este ritual, o mesmo pede autorização aos ancestrais para permitir o início da época e, ao mesmo tempo, pede para que os antepassados abençoem a época. Faz-se o anúncio do balanço da vida da comunidade, das suas intempéries, suas conquistas e roga-se para que haja mais produtividade, sobretudo na colheita. Por outro lado, é o marco do fim da época de ukanyi,

\footnotetext{
${ }^{28}$ Uso o termo para fazer referência a um espírito de convivência em comunhão.

${ }^{29}$ Expressão em xichangana, que significa época de ukanyi.
} 
pois kuphahla aparece também como forma de agradecer aos antepassados por mais uma festa de ukanyi.

Kuphahla é o meio pelo qual se invoca os antepassados. Entretanto, mais do que para invocar os ancestrais, existe também a crença comum de que o mesmo é o meio pelo qual os ancestrais bebem e desfrutam do ukanyi e mantêm-se presentes no ritual. Estas crenças são comportamentos de senso comum que, segundo Garfinkel ${ }^{30}$, são os constituintes necessários de todo o comportamento socialmente organizado, e é assim que os indivíduos vêem, descrevem e propõem em conjunto uma definição da situação social do ritual de ukanyi e do cotidiano em Macuane e Marracuene.

Mas, qual é o significado da morte nas tradições africanas? O que é o antepassado? $O$ que ele representa? Qual a sua relação com o mundo dos vivos?

Segundo Altuna ${ }^{31}$ :

A morte pode ser definida como separação (como ruptura do equilíbrio) dos elementos constitutivos, seguida duma destruição imediata ou progressiva, total ou parcial, de certos elementos, enquanto que os outros são promovidos a um novo destino. [...] Apresenta-se assim como a "destruição do todo" (a pessoa), da sua unidade e harmonia, mas nunca é "destruição de tudo".

Com a morte, parte da pessoa deixa de existir para sempre, finaliza a realidade humana e a sua plenitude ${ }^{32}$. Traz o fim do existir como vivente, o homem fica em "espírito" que somente "existe", sem que jamais seja possível chamar-lhe "vivente"33.

Neste caso, seria a morte uma iniciação? Para Kagame ${ }^{34}$, um intelectual ruandês, a morte é o fim do existir como vivente; "o antepassado passa a ser um 'existente não vivente'” 35.

Segundo Altuna ${ }^{36}$,

o homem morto transforma-se em 'outro ser', 'existe de modo diferente', 'é outra coisa' sem semelhança neste mundo. A morte ocasiona uma mudança de estado porque é uma "passagem" que modifica a personalidade.

Se Altuna ${ }^{37}$ afirma que "o antepassado passa a ser um 'existente não vivente'", eu vou mais além e digo que, o antepassado é um existente vivente. Pois, o antepassado, segundo meus interlocutores, apesar de morto fisicamente ele não deixa de viver, continua a viver num mundo

\footnotetext{
30 GARFINKEL, Harold. Estudos da etnometodologia. Cambridge: Polity presse, 1967.

${ }^{31}$ ALTUNA, Raul. Cultura Tradicional Bantu. 2a ed. Águeda: Paulinas Editora, 2014.

${ }^{32}$ ALTUNA, Raul. Cultura Tradicional Bantu. 2a ed. Águeda: Paulinas Editora, 2014.

${ }^{33}$ KAGAME, Alexis. La philosophie bantu comparée. Paris: Présence africaine, 1976.

${ }^{34}$ Ibidem.

${ }^{35}$ ALTUNA, Raul. Cultura Tradicional Bantu. 2a ed. Águeda: Paulinas Editora, 2014.

${ }^{36}$ Ibidem.

${ }^{37}$ Ibidem.
} 
invisível, e se materializando simbolicamente por meio de práticas cotidianas, nas ações diárias dos indivíduos e nas suas relações uns com os outros, bem como nas suas visões do mundo, ou seja, nas formas como estes concebem e interpretam os contextos nos quais vivem.

Quando durante o ritual os indivíduos deitam ukanyi para o chão para que os antepassados bebam é crendo que estes estão presentes no tempo e no espaço. Quando o ritual de ukanyi decorre com sucesso, acredita-se que na invocação os antepassados ouviram as preces para que tudo decorresse bem e acolheram-nas. E quando o contrário sucede (insucesso) implica que estes ouviram, contudo não as acolheram por algum motivo. Ora, ouvir e reagir ao pedido sugere-nos uma interação antepassados - indivíduos.

Os antepassados/mortos aparecem para os vivos e falam, interagem com eles, tal como revela o adágio popular: "o africano nunca descansa, mesmo após a morte continua trabalhando como antepassado" (conhecimento/adágio popular africano, recolhido durante o trabalho de campo).

Neste sentido, o antepassado tem vida sim, se entendermos a vida não somente do ponto de vista biológico, enquanto existência física, mas também, vida do ponto de vista social, enquanto uma construção sociocultural, vida enquanto o ato de existir, seja espiritualmente ou fisicamente, interagindo e exercendo influência sobre os indivíduos e na sua vida cotidiana.

No pensamento ou filosofia bantu, a morte, apesar de destruição e desordem, aparece como um momento necessário da vida, que brota no nascimento e culmina no estado de antepassado. Entre ser vivo e ser antepassado, dá-se uma continuidade ontológica ${ }^{38}$. 0 antepassado, além de perdurar, prolonga-se na sua descendência.

Os mortos regulamentam as relações entre os membros do grupo. Todos reconhecem as suas regras. A conformidade é total e os excessos individuais coartados. A coesão, a boa ordem, a participação na vida comunitária e nas suas cerimônias, certa igualdade das condições materiais, o respeito mútuo, são assim assegurados sem dificuldade por poderes superiores, sempre atentos, onde a sabedoria expressa a conformidade do homem com a ordem das $\operatorname{coisas}^{39}$. Tal como Deschamps ${ }^{40}$, Altuna ${ }^{41}$ também comunga com esta idéia, pois em seu entendimento, os antepassados desempenham um papel "estabilizador" social básico. Os espíritos ou seres espirituais contribuem para a ordem do mundo e constituem uma verdadeira "chefia celeste" sob a autoridade

\footnotetext{
38 Ibidem.

${ }^{39}$ DESCHAMPS, Hubert. Les religions de l'Afrique Noire, que sais-je? Paris: Presses Univ. De france, 1970.

${ }^{40}$ Ibidem.

${ }^{41}$ ALTUNA, Raul. Cultura Tradicional Bantu. 2ae ed. Águeda: Paulinas Editora, 2014.
} 
de Deus ${ }^{42}$. Por isso, os bantu devem lembrá-los e torná-los propícios. O culto bantu reserva-lhes ritos especiais ${ }^{43}$.

O problema é que, ambos os autores, assim como muitos outros, concebem os mortos, os antepassados só enquanto geradores de ordem social, coesão e equilíbrio, sendo que, estes não só são responsáveis pelo equilíbrio, mas também pelas tensões, conflitos, enfim, pelo desequilíbrio na estrutura social.

Afirmar que, para além da ordem, que pressupõe equilíbrio, os antepassados também geram desequilíbrio, reafirmo as falas de alguns interlocutores segundo os quais, por exemplo, quando algumas normas ritualísticas, de sociabilidade, ou regras sociais são transgredidas pelos indivíduos, os antepassados/mortos, insatisfeitos com tal ação, tomam medidas corretivas, que por vezes podem ser duras, tais como, gerar catástrofes, pestes, etc., no mundo dos vivos, gerando assim um ambiente de tensão e desequilíbrio, como forma de chamar atenção.

Em Marracuene um entrevistado, o Muthombeni dizia:

Nesta época não colhemos muito. Sabes por quê? É porque os antepassados estão zangados. Perdeu-se o respeito à tradição, perdeu-se o respeito aos mais velhos. Hoje em dia se vende ukanyi (a bebida dos antepassados) e segundo a tradição ukanyi não se pode vender porque é uma bebida sagrada e ancestral. Há seca, fome, quase que não chove, a bandidagem aumentou. Tudo isso é castigo deles, os nossos antepassados.

A fúria dos antepassados no que concerne à venda de ukanyi deve-se ao fato de que a comercialização desta bebida é culturalmente proibida, pois isso é entendido como profanação desta e dos antepassados. Deste jeito, o consumo da mesma é de ordem coletiva e compartilhada gratuitamente, remetendo à comensalidade ${ }^{44}$.

Esta última fala sugere, inclusive, que até aspetos ou fenômenos que seriam de causa "natural" e/ou humana (como a seca, falta de chuva, etc.) tem a sua origem no descontentamento dos antepassados.

Para Castiano ${ }^{45}$, filósofo moçambicano, nas tradições religiosas africanas "a vida espiritual após a morte é concebida, de certa forma, numa perspectiva materialista: os antepassados mortos ainda comem e bebem conosco; às vezes são mesmo capazes de nos visitar em casa". Isto porque, para os africanos, viver aqui e agora (mas de forma honrosa e boa) torna-se muito mais importante

\footnotetext{
${ }^{42}$ GRAVRAND, Henry. Les religions africaines traditionelles source de civilisation spirituelle. [S.I.]: [s.n.], 1970.

${ }^{43}$ ALTUNA, Raul. Cultura Tradicional Bantu. 2a ed. Águeda: Paulinas Editora, 2014.

${ }^{44}$ GONÇALVES, José; CONTINS, Marcia. A escassez e a fartura: categorias cosmológicas e subjetividade nas festas do Divino Espírito Santo entre os açorianos imigrantes no Rio de Janeiro. In: CAVALCANTI, Maria L. V. C; GONÇALVES, José R. S. (Orgs). As festas e os dias: ritos e sociabilidades festivas. Rio de Janeiro: Contra Capa Livraria Ltda, 2009.

${ }^{45}$ CASTIANO, José. Referências da filosofia Africana: em busca da intersubjectivação. Maputo: Sociedade Editorial Ndjira, Lda, 2010.
} 
e interessante para a ética religiosa.

Os antepassados vivem também aqui e o agora (o presente), pois, nas tradições religiosas africanas, embora exista a idéia de uma vida após a morte física, esta crença, porém, não leva aos africanos a cultivarem a esperança de um futuro glorioso para além da vida que levam aqui na terra ${ }^{46}$, ou seja, "não existe paraíso no qual teremos uma vida plena e nem um inferno onde teremos uma 'vida horrível depois da morte'"'47. Daí urge a necessidade de os antepassados se manterem não só no mundo dos mortos, mas também, e, sobretudo no mundo dos vivos.

Para Mbiti ${ }^{48}$, um filósofo africano oriundo do Quênia, o tempo atual implica e contém automaticamente o passado. O tempo, entre os africanos, move-se em direção ao passado e não ao futuro. O que contribui para que os antepassados, apesar de pertencerem ao passado, continuem se mantendo presentes nas vidas dos macuanenses e marracuenenses, compondo ou como parte integrante da estrutura social de Macuane e Marracuene.

Altuna ${ }^{49}$, referindo-se ao mundo dos mortos, dos antepassados, como "invisível" argumenta que "o mundo invisível está povoado de espíritos, gênios e antepassados com diferentes modalidades". Por não esclarecer a sua identidade, sugere o autor, cometeram-se erros ao descrevê-los ou arbitrariamente se estabeleceram diversos e estratificados panteões. Todavia, a pirâmide vital e o monoteísmo bantu evitam qualquer confusão. Deus, Único e Criador, permanece num âmbito superior qualitativamente diferente ${ }^{50}$.

"Os espíritos, gênios e antepassados nunca usurpam o lugar de Deus, mesmo que pela participação ocupem um lugar preponderante. O bantu situa-os como intermediários entre a divindade e os vivos. Há muitas expressões que Ihes atribui esta mediação" ${ }^{51}$. Este fato fica evidente com uma das falas do mukhulu/hosi de Macuane, José Maria Albuquerque Cossa, proferidas em uma das conversas que tive com ele, na qual sustenta que: "na nossa religião tradicional, a árvore sagrada chamada gandzelo é como se fosse nosso altar, representa o lugar onde invocamos e nos comunicamos com os nossos antepassados, inclusive com Deus [...]". Portanto, segundo esta visão, onde estão os antepassados está Deus e vice-versa.

Estes intermediários são concebidos pelo bantu como "mensageiros de Deus". A sua presença ativa abrange o mundo invisível tão real como o visível. Os dois mundos ficam

\footnotetext{
${ }^{46}$ Ibidem.

${ }^{47} \mathrm{MBITI}$, John. African religions and philosophy. Nairobi, Kampala, Dar es Salam: East African Educational Publishers, 1969.

48 Ibidem.

${ }^{49}$ ALTUNA, Raul. Cultura Tradicional Bantu. 2a ed. Águeda: Paulinas Editora, 2014.

50 Ibidem.

51 Ibidem.
} 
independentes; com o seu poder determinam vastas esferas do mundo visível que, por sua vez, condiciona com o seu culto revitalizador a permanência pujante dos antepassados ${ }^{52}$.

É compreensível a idéia de Altuna ${ }^{53}$ de que os dois mundos (invisível e visível) com o seu poder determinam vastas esferas do mundo visível que, por sua vez, condiciona com o seu culto revitalizador a permanência pujante dos antepassados. Não obstante, o mundo visível e o mundo invisível não são tão independentes como o autor sugere, mas sim interdependentes, pois entre eles existe uma reciprocidade. Tal que, a presença dos antepassados no mundo visível é perpetuada também pelos indivíduos, na medida em que estes reproduzem rituais de culto aos antepassados, garantindo a sua permanência de geração em geração.

Por sua vez, os indivíduos necessitam da presença e do poder ancestral na sua vida para desencadear suas ações e práticas cotidianas. Como então o autor pode conceber ambos os mundos como independentes? Esta idéia é contraditória e confusa.

Em suma, a presença dos antepassados no mundo visível não depende só do poder destes, mas também dos indivíduos que habitam o mesmo, daí que existe uma profunda interdependência entre eles que garante esta relação. A relação entre o mundo visível e o mundo invisível não é de dominação, mas sim de reciprocidade, na medida em que os antepassados permanecem presentes e condicionam a vida do mundo visível e, por sua vez, a sua permanência neste mundo depende, em parte, dos indivíduos mediante a realização de cultos revitalizadores. Contudo, é uma relação nem sempre pacífica, mas também conflitual, na qual existe uma disputa de forças humanas e espirituais, e é essa relação conflitual que permite o "movimento" ou uma dinâmica no mundo dos vivos.

No dia 2 de fevereiro de 2016, fui à cerimônia de Gwaza Muthini, nome pelo qual ficou conhecida a batalha de resistência contra a ocupação colonial portuguesa travada em Marracuene por volta de 1895, concretamente no dia 2 de fevereiro. Assim, a festa de Gwaza Muthini é celebrada todos os anos na mesma data em memória dos guerreiros que tombaram na luta contra a dominação colonial.

Esta cerimônia é imprescindível e incontornável na nossa análise visto que, embora a princípio não tendo uma relação direta com o ritual de ukanyi, ela coincide com a época de ukanyi e consequentemente a bebida ancestral-sagrada é uma das usadas para o ato ritual. E mais ainda, é que pelo que constatei no trabalho de campo, um dos grandes motivos que leva os indivíduos a deslocarem-se em massa à vila de Marracuene nesta data ( 2 de fevereiro), é a possibilidade ou

\footnotetext{
52 Ibidem.

53 Ibidem.
} 
oportunidade de beber a tradicional e sagrada bebida - ukanyi. Assim, ambas as cerimônias acabam estando estritamente interligadas.

Desta feita, analisar a cerimônia de Gwaza Muthini ou certas situações sociais desta, permite também, de modo geral, compreender melhor a estrutura social de Marracuene, entender a forma como a relação entre os vivos e os mortos emana nesta festa e perceber como os espaços sociais se transformam com a realização de certos eventos.

Importante salientar que a cerimônia de Gwaza Muthini insere um conjunto de performatividades que envolvem uma série de práticas autóctones que se juntam às modernas e possibilitam-nos vislumbrar e compreender a relação entre a tradição e a modernidade.

Nesse dia, cheguei bem cedo a Marracuene e a vila já estava bem agitada, um movimento jamais visto em dias "normais" (caracterizados por um fluxo menor de transeuntes e ambiente mais calmo).

Havia barracas montadas em tudo quanto era canto daquela urbe, as calçadas tinham sido tomadas por barracas improvisadas, de tal forma que os pedestres tinham perdido seu espaço, passando a compartilhar o mesmo espaço com automóveis. Transeuntes de diversos lugares e automóveis compunham as ruas da vila de Marracuene e o comércio tinha se intensificado. Palcos e tribunas montados no local da cerimônia, num monumento em memória dos guerreiros da batalha de Gwaza Muthini. Estava tudo ornamentado e com um ar colorido e festivo.

As autoridades tradicionais já lá estavam para iniciar a cerimônia, esta que começou com um ritual denominado kuphahla (ritual através do qual se estabelece a comunicação com os antepassados). E, segundo as autoridades tradicionais o ritual kuphahla, pelo menos em Marracuene, só pode ser realizado bem cedo, de manhã, e não num outro período do dia, pois se acredita que nesse período os espíritos dos antepassados ainda não começaram a vaguear, estão ainda em repouso, sendo que ficam então disponíveis para uma comunicação com o mundo.

O ritual consistiu em os líderes tradicionais deitarem para o chão junto ao monumento em memória dos guerreiros de Gwaza Muthini a bebida ancestral-sagrada ukanyi e outra bebida tradicional de nome uputsu ou xinto e ainda vinho, proferindo alguns discursos que estavam relacionados, sobretudo ao pedido de paz, visto que Moçambique passava por um momento de crise política; pedido de chuva, tendo em conta que a seca assolava o país e pedido de tranquilidade, uma vez que Marracuene passava por um dia de muita agitação naquele dia festivo.

Feito isso, alguns membros do governo que já eram esperados chegaram e se juntaram à massa ali presente. Ora, é preciso salientar um detalhe: é que, na verdade, o ritual tinha que ter iniciado com a presença dos membros do governo como o governador da Província de Maputo, o 
ritual seria dirigido pelas autoridades tradicionais, mas na presença do governador, uma vez que existe uma articulação entre ambos (autoridade tradicional vs autoridade "moderna"). Todavia, o ritual acabou iniciando sem o governador e seu elenco, devido à sua demora.

No meio de tudo isto, os líderes tradicionais queixavam-se dos membros do governo pelo atraso, pois o atraso era visto como um desrespeito aos antepassados, à tradição, e isto deixou um ambiente de tensão entre ambas as estruturas. Na visão do campo "tradicional", não é qualquer hora do dia que se estabelece a comunicação com os ancestrais, nem sempre os antepassados estão disponíveis.

Desta forma, na estrutura social da vila de Marracuene, apesar de os antepassados estarem presentes o momento todo na vida das pessoas, a comunicação com os mesmos respeita ou segue alguns momentos específicos. A noção de tempo é fundamental para a comunicação com os antepassados. Ou seja, a noção de tempo é crucial para compreender em que base se assenta a relação entre os indivíduos (marracueneses) e os ancestrais, entre o mundo dos vivos e o mundo dos mortos.

Outro episódio interessante de pensar pelo fato de ter uma carga da relação "indivíduos antepassados" foi a minha entrada na mata sagrada de Marracuene, na qual eu e meu colaborador de campo, Netabu e demais participantes fomos convidados a descalçar e a deixar o calçado na entrada. Foi então quando me dei conta de que, no ritual, quase todos estavam sem calçado. Procurei saber o "por quê" e explicaram-me que aquele ato simbolizava o respeito que se deve ter com os antepassados, e uma forma de manifestar respeito era andar descalço, pois, os ancestrais andavam descalços, nem sequer conheceram o sapato.

Portanto, apresentar-se minimamente à semelhança dos antepassados era uma forma de honrá-los. Mas, sobretudo, o andar descalço era uma forma de manter um contato direto entre os indivíduos e os antepassados mediante o contato entre o corpo (os pés) e a terra. Isso era uma condição importante para manter a comunicação com os espíritos dos antepassados.

Esta posição tem sustento na fala de um entrevistado que vou tratá-lo de Djoka:

Essas coisas de sapato são de hoje, os nossos antepassados andavam descalços, pisando o chão direto, sentindo a terra firme e mantendo contato com a natureza. É por isso que nós também temos que valorizar, respeitar e manter essa tradição, para o nosso bem e para que as próximas gerações também sigam isso [...] caso não, se calhar pode haver desgraça aqui em Marracuene [...].

A fala de Djoka desvenda-nos mais um dado. É que a transgressão da "tradição", o desrespeito aos antepassados pode resultar numa desgraça qualquer em Marracuene, ou seja, a 
transgressão gera desequilíbrio, este que é comandado pelos antepassados.

Uma nota importante é que, tanto em Macuane bem como Marracuene o ritual de ukanyi só se realiza mediante a ida a mata sagrada onde repousam os antepassados das famílias reais Cossa (Macuane) e Mabjaia (Marracuene), que representam os antepassados comuns ${ }^{54}$ desses contextos sociais, com o intuito de estabelecer uma comunicação com os mesmos (antepassados). Comunicação essa que é mediada pelos líderes (tihosi - plural de hosi) Cossa, no caso de Macuane e Mabjaia em Marracuene, como por outros líderes tradicionais. Desta maneira, este fato fortalece a idéia da existência da interação contínua entre os vivos e os mortos, sendo que o ritual de ukanyi abre espaço para essa possibilidade de interação.

Dessarte, tal como pontua Mauss ${ }^{55}$, que a primeira troca dos homens teria sido com os mortos/deuses, é importante compreender como essa relação se processa nos dias que correm.

Nas condições expostas em toda esta discussão sugerida, nota-se claramente a importância dos mortos na vida dos indivíduos e vice-versa nas tradições africanas, no geral, e nas tradições macuanenses e marracuenenses, em particular.

Deste modo, se a estrutura social de Macuane e Marracuene é constituída por um sistema de valores, crenças, então, uma prática social, um ritual como mhamba ya ukanyi, respectivamente, pode estabelecer uma mediação entre o mundo dos vivos e o mundo dos mortos, possibilitando a visibilização do invisível, ou seja, tornando visível um mundo concebido como invisível, no caso, o mundo dos mortos.

Assim sendo, provisoriamente, posso adiantar que o ritual de ukanyi estabelece a mediação entre o mundo dos vivos e o mundo dos mortos através da presença dos antepassados, seja no ritual, ou nas práticas e ações cotidianas dos indivíduos. E, por sua vez, o ritual de ukanyi aparece como um culto revitalizador da permanência dos antepassados (mortos) no mundo dos vivos. Sendo que estes (os antepassados) se mantêm presentes no cotidiano, nas práticas e ações dos indivíduos em Macuane e Marracuene. Ademais, condicionam a vida social. Os mortos, embora defuntos e pertencentes ao passado, continuam presentes no dia a dia dos indivíduos bem como influenciam a sua conduta comportamental, modificando suas ações diárias. É neste ciclo espacio-temporal que o movimento entre o mundo dos vivos e dos mortos se mantém.

Afirmar que os antepassados se fazem presentes no cotidiano dos indivíduos e modificam o

\footnotetext{
${ }^{54}$ Antepassados comuns refiro-me aqueles que representam toda a comunidade e não somente a uma família em particular. E neste caso, estes tem sido os antepassados da família real.

${ }^{55}$ MAUSS, Marcel. Sociologia e Antropologia. São Paulo: Cosac Naif, 2003.
} 
curso de suas vidas e das coisas é tal como afirma o filósofo moçambicano Castiano ${ }^{56}$ que, nas tradições religiosas africanas, "os antepassados mortos ainda comem e bebem conosco; às vezes são mesmo capazes de nos visitar em casa". Sendo os responsáveis pelo equilíbrio e desequilíbrio social.

\section{Considerações finais}

Com a discussão levantada acima posso afirmar que o ritual de ukanyi é inegavelmente um mediador entre o mundo dos vivos e o mundo dos mortos. Sendo que, a presença dos antepassados no ritual, bem como sua relação com os indivíduos são elementos fundamentais dessa mediação. Assim, o ritual de ukanyi revitaliza a relação entre ambos os mundos, visto que permite um entrelaçamento entre eles.

O ritual de ukanyi é uma cerimônia festiva que permite a exaltação dos antepassados, ativa e reativa valores, crenças e práticas que fortalecem e revigoram a religiosidade tradicional africana. Posso assim dizer que, o mesmo possibilita-nos vivenciar e experimentar dois mundos diferentes em simultâneo, o mundo dos vivos e o mundo dos mortos, ou seja, um mundo visível e outro invisível. Ora, a relação entre estes dois mundos pode ser de interdependência e/ou também remeter a tensões, o que significa que em alguns momentos pode sugerir-nos certa estabilidade e noutros, instabilidade.

O fato de a relação entre o mundo dos antepassados e o mundo dos vivos ser de interdependência, tensões, conflitos, remete a pensar que a mesma é de negociação e renegociação constante e contínua.

Embora alguns autores pensem o antepassado como um "existente não vivente", a experiência do ritual de ukanyi em Macuane e Marracuene permite-nos compreender o antepassado também como um "existente vivente". Pois, o antepassado apesar de morto fisicamente ele não deixa de viver, continua a viver num mundo invisível, e se materializando simbolicamente no mundo visível. Sendo assim, os antepassados e os indivíduos nos contextos estudados são ambos "existentes viventes", se diferenciando na peculiaridade da sua forma de vivência.

Os antepassados (mortos) aparecem para os vivos, falam e interagem com eles. Portanto, o antepassado tem vida, se entendermos a vida enquanto uma construção sociocultural, enquanto o

56 CASTIANO, José. Referências da filosofia Africana: em busca da intersubjectivação. Maputo: Sociedade Editorial Ndjira, Lda, 2010. 
ato de existir, seja fisicamente ou espiritualmente, interagindo e exercendo influência sobre os indivíduos e na sua vida cotidiana. Daí afirmo que, o mundo dos antepassados e o dos vivos se constituem como mundos tão "distantes" quanto "próximos".

As crenças e práticas do ritual de ukanyi são constituintes das religiões tradicionais africanas (RTA) a partir das quais os indivíduos dão sentido/significado às suas vidas assim como interpretam e compreendem o mundo em que vivem.

Destarte, compreender a relação entre o mundo dos vivos e o mundo dos antepassados é adentrar na forma como se constituem as afrofilosofias que permitem tangenciar o contexto africano. Portanto, atravessando os modos de agir, sentir, pensar e existir dos indivíduos de Macuane e Marracuene, em particular, e dos moçambicanos, no geral.

\section{Referências bibliográficas}

ALTUNA, Raul. Cultura Tradicional Bantu. 2a ed. Águeda: Paulinas Editora, 2014.

CASTIANO, José. Referências da filosofia Africana: em busca da intersubjectivação. Maputo: Sociedade Editorial Ndjira, Lda, 2010.

COSSA, Dulcídio. Mhamba ya ukanyi (O ritual de ukanyi): uma tradição na modernidade entrelaçamentos do rural e urbano. Dissertação (Mestrado em Ciências Sociais). Universidade do Estado do Rio de Janeiro, Rio de Janeiro, 2017.

DESCHAMPS, Hubert. Les religions de l'Afrique Noire, que sais-je? Paris: Presses Univ. De France, 1970.

DURKHEIM, Émile. A divisão social do trabalho. Rio de Janeiro: Martins Fontes, 2000.

GARFINKEL, Harold. Estudos da etnometodologia. Cambridge: Polity presse, 1967.

GLUCKMAN, Max. Custom and Conflit in Africa. Oxford: Blackwell, 1995.

GONÇALVES, José; CONTINS, Marcia. A escassez e a fartura: categorias cosmológicas e subjetividade nas festas do Divino Espírito Santo entre os açorianos imigrantes no Rio de Janeiro. In: CAVALCANTI, Maria L. V. C; GONÇALVES, José R. S. (Orgs). As festas e os dias: ritos e sociabilidades festivas. Rio de Janeiro: Contra Capa Livraria Ltda, 2009.

GRAVRAND, Henry. Les religions africaines traditionelles source de civilisation spirituelle. [S.I.: s.n.], 1970.

KAGAME, Alexis. La philosophie bantu comparée. Paris: Présence africaine, 1976.

MAUSS, Marcel. Sociologia e Atropologia. São Paulo: Cosac Naif, 2003.

MBITI, John. African religions and philosophy. Nairobi, Kampala, Dar es Salam: East African Educational Publishers, 1969. 
PEREIRA, Rinaldo. Pontencialidades do jogo africano Mancala IV para o campo da educação matemática, história e cultura africana. Tese (Doutorado em Educação). Universidade Federal do Ceará, Fortaleza, 2016.

TURNER, Victor. O Processo Ritual: estrutura e anti-estrutura. Petrópolis: Editora Vozes, 2013.

VAN GENNEP, Arnold. Os ritos de passagem. Petrópolis: Editora Vozes, 2011.

Dulcídio Manuel Albuquerque Cossa: Também conhecido pelo seu nome africano Nyimpini Khosa. Doutorando em Ciências Sociais e Bolsista CNPq - Brasil. Mestre em Ciências Sociais. Universidade do Estado do Rio de Janeiro (UERJ). Programa de Pós-graduação em Ciências Sociais (PPCIS). Instituto de Ciências Sociais (ICS). Departamento de Antropologia. Antropólogo e Sociólogo.

Artigo recebido para publicação em: Outubro de 2018.

Artigo aprovado para publicação em: Janeiro de 2019. 